Article

\title{
Geopolymer Based on Mechanically Activated Air-cooled Blast Furnace Slag
}

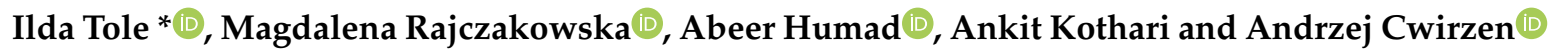 \\ Building Materials, Department of Civil, Environmental and Natural Resources Engineering, Luleå University of \\ Technology, 97187 Luleå, Sweden; magdalena.rajczakowska@ltu.se (M.R.); abeer.humad@ltu.se (A.H.); \\ ankit.kothari@ltu.se (A.K.); andrzej.cwirzen@ltu.se (A.C.) \\ * Correspondence: ilda.tole@ltu.se
}

Received: 16 February 2020; Accepted: 28 February 2020; Published: 4 March 2020

\begin{abstract}
An efficient solution to increase the sustainability of building materials is to replace Portland cement with alkali-activated materials (AAM). Precursors for those systems are often based on water-cooled ground granulated blast furnace slags (GGBFS). Quenching of blast furnace slag can be done also by air but in that case, the final product is crystalline and with a very low reactivity. The present study aimed to evaluate the cementitious properties of a mechanically activated (MCA) air-cooled blast furnace slag (ACBFS) used as a precursor in sodium silicate alkali-activated systems. The unreactive ACBFS was processed in a planetary ball mill and its cementing performances were compared with an alkali-activated water-cooled GGBFS. Mixes based on mechanically activated ACBFS reached the 7-days compressive strength of $35 \mathrm{MPa}$ and the 28-days compressive strength $45 \mathrm{MPa}$. The GGBFS-based samples showed generally higher compressive strength values.
\end{abstract}

Keywords: mechanochemistry; alkali activation; air-cooled slag; ground granulated slag; mechanical activation; cement-free mortars

\section{Introduction}

The production of Portland cement uses processing temperatures exceeding $1400{ }^{\circ} \mathrm{C}$, thus leading to a large $\mathrm{CO}_{2}$ footprint [1]. Environmental benefits can be achieved by the use of binders made of $\mathrm{CO}_{2}$ neutral alumina silicate rich industrial by-products or wastes. Fly ash and ground granulated blast furnace slag (GGBFS) are typical examples. The GGBFS, which is in the focus of this research, can be utilized either as partial or full replacement of Portland cement. In the case of partial replacement, the GGBFS undergoes a secondary pozzolanic reaction due to the alkali activation process induced by the hydrating Portland cement [2]. At full replacement, the solidification is controlled by a combination of alkali activation processes and hydration. The chemical reactions are induced by strong alkalis such as sodium silicate or sodium hydroxide [3-6].

Blast furnace slag (BFS) is a by-product of iron production in a blast furnace. The global production of slag is estimated to reach around 450 million tons per year and the value is expected to increase in the coming years [7]. In the process, a mixture of pelleted iron oxides, limestone and carbon is heated at around $1500{ }^{\circ} \mathrm{C}$. The formed liquid slag is removed from the blast furnace and can be cooled in different ways (e.g., by air-cooling, air quenching, water spraying, water quenching, etc.) [8].

The applied quenching method affects the properties of the produced BFS, especially including its crystallinity. The obtained solid material can be crushed and grinded, producing the GGBFS. The water-cooled GGBFS is highly amorphous, has strong pozzolanic properties and good reactivity in alkali-activated systems. Unfortunately, the demand for large amounts of water during quenching produces pollution and negatively affects the environment [9]. 
An alternative quenching method based on air-cooling produces a crystalline material, air-cooled blast furnace slag (ACBFS), which is unreactive and is mainly used as coarse aggregate for road bases and concrete production [10-12]. Earlier studies showed that mechanical activation is able to induce amorphization and structural disorder through the application of high-energy impact forces during grinding leading to the increased chemical reactivity $[13,14]$. Different mechanically activated minerals showed significant enhancement of their chemical reactivity [15-19].

The main aim of this study was to verify if ACBFS could be activated by the application of intensive grinding and to produce reactivity similar to the water-cooled BFS.

\section{Materials and Methods}

ACBFS and water-cooled GGBFS were used as precursors for this study. Both materials originated from the same source. Their chemical composition was similar but with a slightly higher amount of the $\mathrm{Fe}_{2} \mathrm{O}_{3}$ in the case of the air-cooled slag (ACBFS) (Table 1).

Table 1. Chemical composition of air-cooled blast furnace slag (ACBFS) and ground granulated blast furnace slag (GGBFS) by treatment.

\begin{tabular}{cccccccccc}
\hline & $\mathbf{S i O}_{\mathbf{2}}$ & $\mathbf{A l}_{\mathbf{2}} \mathbf{O}_{\mathbf{3}}$ & $\mathbf{C a O}$ & $\mathbf{F e}_{\mathbf{2}} \mathbf{O}_{\mathbf{3}}$ & $\mathbf{K}_{\mathbf{2}} \mathbf{O}$ & $\mathbf{M g O}$ & $\mathbf{M n O}$ & $\mathbf{N a}_{\mathbf{2}} \mathbf{O}$ & $\mathbf{L O I}$ \\
\hline ACBFS & 31.3 & 11.9 & 31.1 & 1.67 & 0.639 & 13.7 & 0.291 & 0.515 & -1.6 \\
GGBFS & 34 & 11.6 & 30.3 & 0.291 & 0.811 & 12.1 & 0.516 & 0.531 & -0.9 \\
\hline
\end{tabular}

ACBFS was mechanically processed using a planetary ball mill with a $500 \mathrm{~mL}$ capacity. The used ball mill was a Retsch equipment, type PM100 (Retsch GmbH, Haan, Germany), with 12 balls having a diameter of $200 \mathrm{~mm}$. The rotation speed was $500 \mathrm{rpm}$. Ball to powder ratio of 25 and grinding duration of 20 min were used for all grindings.

Successively, 54 types of mortars were prepared for the analysis. Combinations of various parameters were selected based on the full factorial design of experiments (Table 2). The water to binder $(\mathrm{w} / \mathrm{b})$ ratio was $0.45,0.5$ and 0.55 . The mass ratio of sand to slag was kept constant at $1: 1$. All mixes were activated by the liquid sodium silicate (SS) provided by the PQ Corporation (PQ Corporation, Valley Forge, PA, USA). The SS had an alkali modulus (AM, mass ratio $\left.\mathrm{SiO}_{2} / \mathrm{Na}_{2} \mathrm{O}\right)$ of 2.2, with 34.37 wt. $\%$ of $\mathrm{SiO}_{2}, 15.6$ wt. $\%$ of $\mathrm{Na}_{2} \mathrm{O}$ and a solid content of 49.97 wt.\%. The AM of the SS was adjusted to reach three different values of $1,1.5$ and 2.0 by addition of sodium hydroxide pellets (98\% purity). Water contained in the sodium silicate solution was subtracted from the calculated w/b ratio. The alkali activator was added as 10, 15 and $20 \mathrm{wt} . \%$ of the binder content calculated as a solid material.

Table 2. Mix composition and sample identification. MCA-ACBFS: Mechanically activated ACBFS.

\begin{tabular}{cccccccc}
\hline & & \multicolumn{3}{c}{ MCA-ACBFS } & \multicolumn{3}{c}{ GGBFS } \\
\cline { 3 - 8 } & & \multicolumn{3}{c}{ Water/Binder } & \multicolumn{3}{c}{ Water/Binder } \\
\hline Alkali Modulus & SS (wt. $\%)$ & $\mathbf{0 . 4 5}$ & $\mathbf{0 . 5}$ & $\mathbf{0 . 5 5}$ & $\mathbf{0 . 4 5}$ & $\mathbf{0 . 5}$ & $\mathbf{0 . 5 5}$ \\
\hline 1 & 10 & A45110 & A5110 & A55110 & G45110 & G5110 & G55110 \\
1 & 15 & A45115 & A5115 & A55115 & G45115 & G5115 & G55115 \\
1 & 20 & A45120 & A5120 & A55120 & G45120 & G5120 & G55120 \\
1.5 & 10 & A451510 & A51510 & A551510 & G451510 & G51510 & G551510 \\
1.5 & 15 & A451515 & A51515 & A551515 & G451515 & G51515 & G551515 \\
1.5 & 20 & A451520 & A51520 & A551520 & G451520 & G51520 & G551520 \\
2 & 10 & A45210 & A5210 & A55210 & G45210 & G5210 & G55210 \\
2 & 15 & A45215 & A5215 & A55215 & G45215 & G5215 & G55215 \\
2 & 20 & A45220 & A5220 & A55220 & G45220 & G5220 & G55220 \\
\hline
\end{tabular}

Mortar, produced using only the not-treated ACBFS as a precursor, did not solidified. Therefore, only samples prepared with the mechanically activated ACBFS (MCA-ACFBS) are included in this study. 
Workability was determined by means of the in-house developed mini slump flow test. The used cone had the following dimensions $d=31.1, \mathrm{D}=44.4$ and $\mathrm{h}=32.5$ (Figure 1 ). The slump flow diameter was calculated as an average of two measured values.

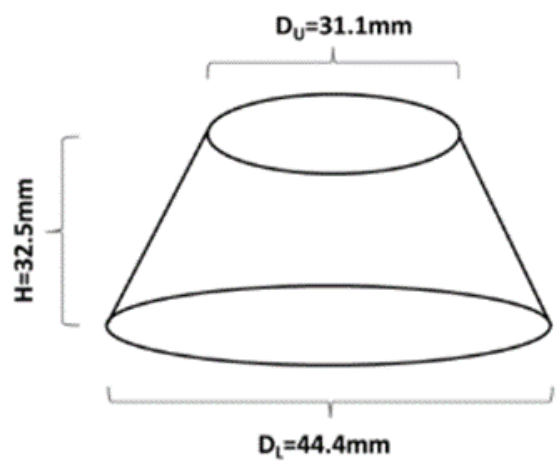

Figure 1. Schematic representation of the mini slump cone used to evaluate the workability.

All mixes were produced using a small volume vacuum mixer, type Ecovac. Mixing duration was $2 \mathrm{~min}$ and the mixing speed was $390 \mathrm{rpm}$. The test specimens had dimensions of $12 \times 12 \times 60 \mathrm{~mm}^{3}$ and were cast into Teflon molds without application of demolding oil. Three samples were prepared for each mix. After demolding, all samples were stored in plastic boxes exposed to laboratory conditions until testing. The compressive strength was determined after 7 and 28 days, using a CTM test machine combined with the QuantumX MX440B universal measuring amplifier (HBM, Darmstadt, Germany), (Figure 2). The loading speed was $0.5 \mathrm{~mm} / \mathrm{min}$. The compressive strength results were calculated as an average of three different measurements.

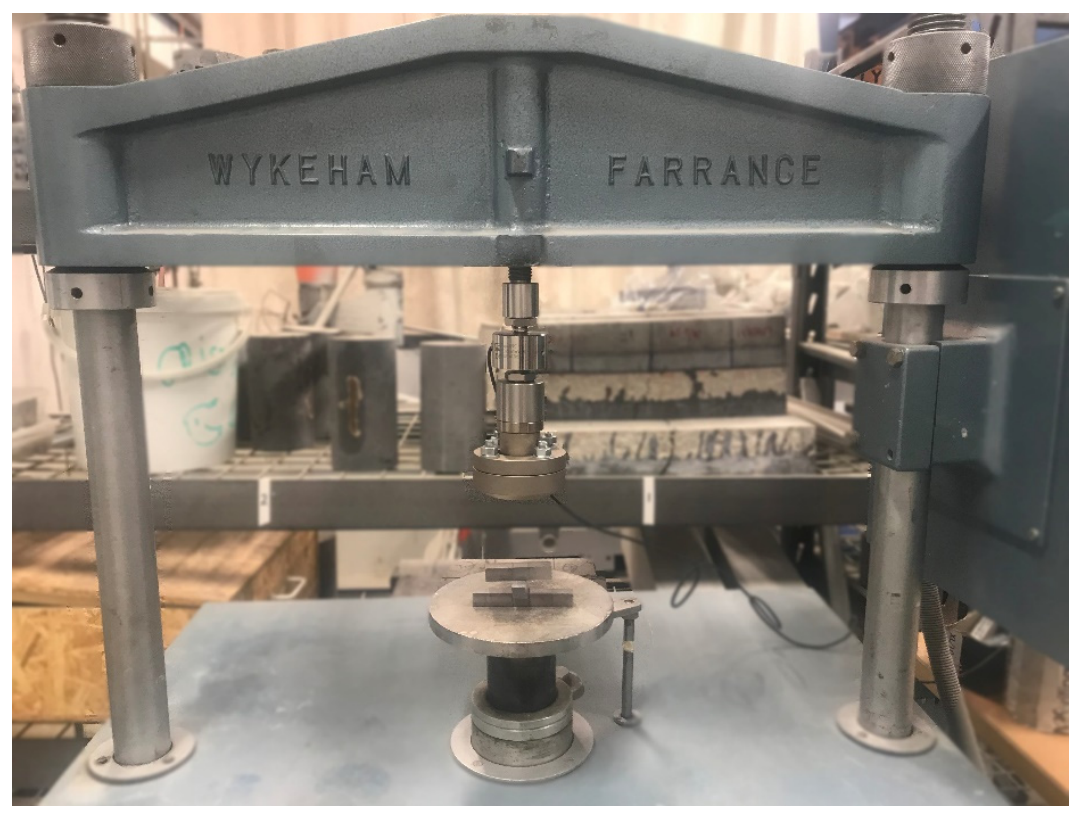

Figure 2. Image of the compressive strength test settings.

An X-ray diffractometer type Empyrean from PANalytical with PIXcel 3D detector (Malvern Panalytical Ltd., Royston, UK) was used to determine the chemical phase composition of the solidified mortars. Measurements were done using $\mathrm{Cu}-\mathrm{K}$ radiation with a wavelength of $1.54060 \AA$, generated at $45 \mathrm{kV}$ and $40 \mathrm{~mA}$. The step size was 0.0260 . The measurements were done from a range of the angle $2 \theta$ from $5^{\circ}$ to $45^{\circ}$. No pre-treatment and back-loading sample holders were used. Panalytical's Highscore Plus software, equipped with a COD database, was used to determine the phase composition. 
Microstructure of the solidified samples was analyzed using Scanning Electron Microscope, type Jeol JSM-IT100 combined with EDS analyzer, type Bruker (JEOL Nordic AB, Sollentuna, Sweden). Samples were stored for $24 \mathrm{~h}$ in isopropanol and subsequently placed in a vacuum chamber and impregnated with a low viscosity epoxy resin. The impregnation was done 7 and 28 days after casting. After curing, samples were grinded and polished using diamond spray containing 9, 3 and $1 \mu \mathrm{m}$ diamond particles.

All images were obtained using a backscattered electron detector at two magnifications: $1000 \times$ for the particle size analysis and $4000 \times$ for the phase composition analysis. The following parameters were used: accelerating voltage of $15 \mathrm{kV}$, accelerating current of $60 \mu \mathrm{A}$, low vacuum mode of $60 \mathrm{~Pa}$. The phase composition analysis was performed on 10 images having the magnification of $4000 \times$ while the EDS spot analysis was used to collect data from 20 different locations on each image. The analyzed points were chosen manually based on the grey level histogram [20].

The particle size distribution was calculated using SEM images having a spatial resolution of $0.025 \mu \mathrm{m}$ per pixel. The image processing and analysis was performed with the ImageJ software [21-23]. The median filter with 2-pixel kernel was applied to remove the noise followed by an automatic thresholding enabling binarization of images. Powder particles were segmented from the impregnating resin matrix. The analysis of the binarized images included determination of the basic morphological parameters (i.e., Feret diameter, perimeter, and surface area).

\section{Results and Discussion}

The suitability of precursors in respects to their chemical composition for alkali-activated systems can be determined by the alkalinity factor $\mathrm{Kb}$ and the so-called hydration modulus (HM). Alkaline and neutral slags are considered to be valuable precursors for alkali-activated materials. Evaluation of the utilized slag alkalinity was calculated as the ratio between the amounts of basic and acid oxides using Equation (1) [24-26]. Slags with a Kb equal to 1 were classified as neutral, while $\mathrm{Kb}>1$ slag was considered basic and $\mathrm{Kb}<1$ as acidic.

$$
\mathrm{K}_{\mathrm{b}}=\frac{\mathrm{CaO}+\mathrm{MgO}+\mathrm{Fe}_{2} \mathrm{O}_{3}+\mathrm{K}_{2} \mathrm{O}+\mathrm{Na}_{2} \mathrm{O}}{\mathrm{SiO}_{2}+\mathrm{Al}_{2} \mathrm{O}_{3}},
$$

The hydration modulus was defined as the ratio between the sum of calcium, magnesium and aluminum oxides and the silicon oxides using Equation (2). Values of the hydration modulus (HM) higher than 1.4 were assumed to indicate efficient hydration during the alkali activation process $[27,28]$.

$$
\mathrm{HM}=\frac{\mathrm{CaO}+\mathrm{MgO}+\mathrm{Al}_{2} \mathrm{O}_{3}}{\mathrm{SiO}_{2}},
$$

According to the calculated values, the MCA-ACBFS were classified as a basic slag, while the GGBFS were slightly acidic. The hydration modulus was higher than 1.4 indicating good hydration properties. In addition, MCA-ACBFS had a higher hydration modulus than the water cooled GGBFS (Table 3).

Table 3. Basicity coefficient and hydration modulus of MCA-ACBFS and GGBFS. HM: Hydration modulus.

\begin{tabular}{ccc}
\hline & $\mathbf{K}_{\mathbf{b}}$ & $\mathbf{H M}$ \\
\hline MCA-ACBFS & 1.10 & 1.81 \\
GGBFS & 0.96 & 1.58 \\
\hline
\end{tabular}

The applied MCA process on ACBFS resulted in finer particles size distribution in comparison with the water-cooled GGBFS (Figure 3). Fragmentation of ACBFS particles was visible from the 
obtained SEM micrographs. The average particle size of the GGBFS sample was approximately $1.8 \mu \mathrm{m}$, while the average particle size of ACBFS sample after the ball milling (BM) process was only $1 \mu \mathrm{m}$.
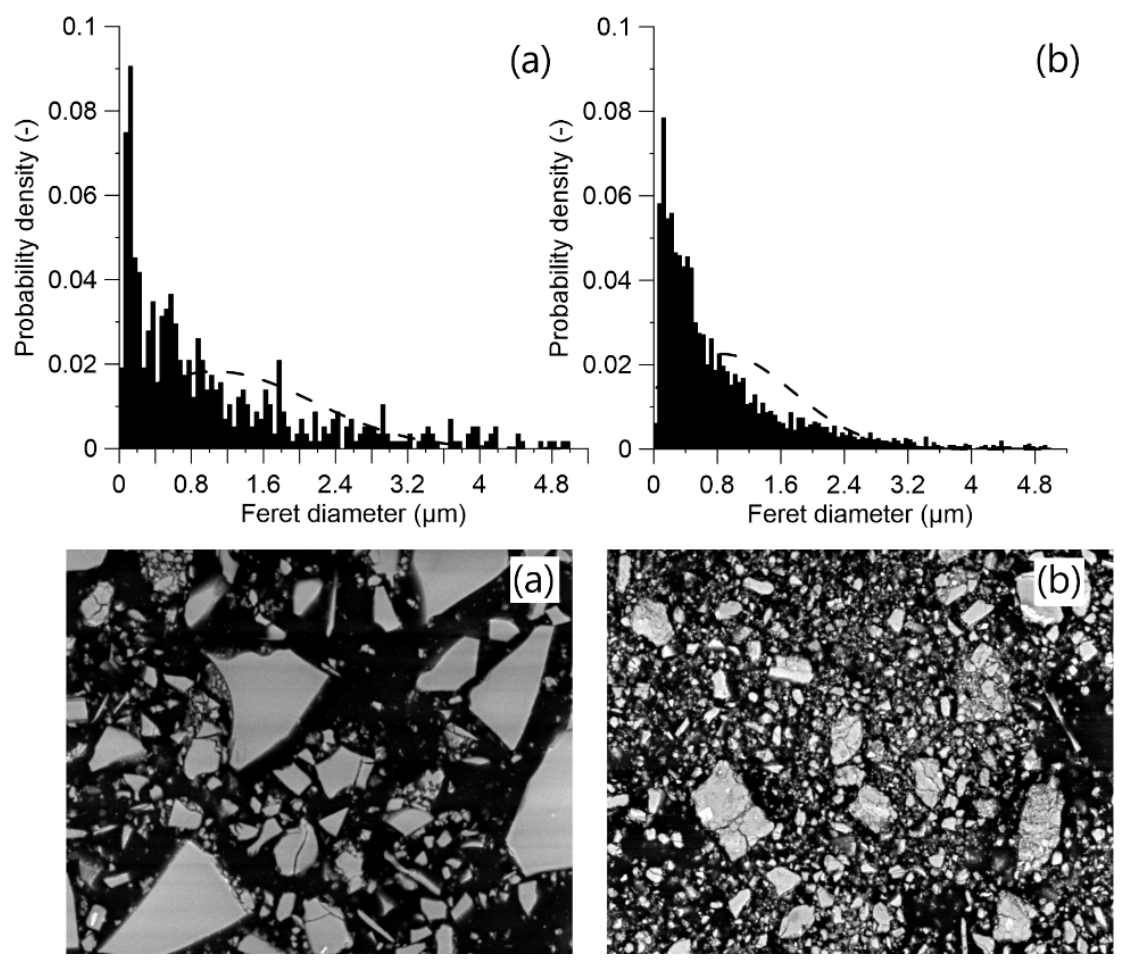

Figure 3. Particle size distribution for: (a) water cooled GGBFS and (b) MCA-ACBFS before alkali activation.

XRD analysis was used to identify changes of the crystallinity after application of the mechanical activation process $[29,30]$. The XRD diagrams showed significant differences between the ACBFS and the GGBFS as well as MCA-ACBFS (Figure 4). The untreated ACBFS contained crystalline akermanite (A), melilite (Ml) and merwinite (Me). Application of the BM process resulted in a partial destruction of $\mathrm{A}$ and $\mathrm{Ml}$ phases, visible as decreased intensities and broadened peak areas.

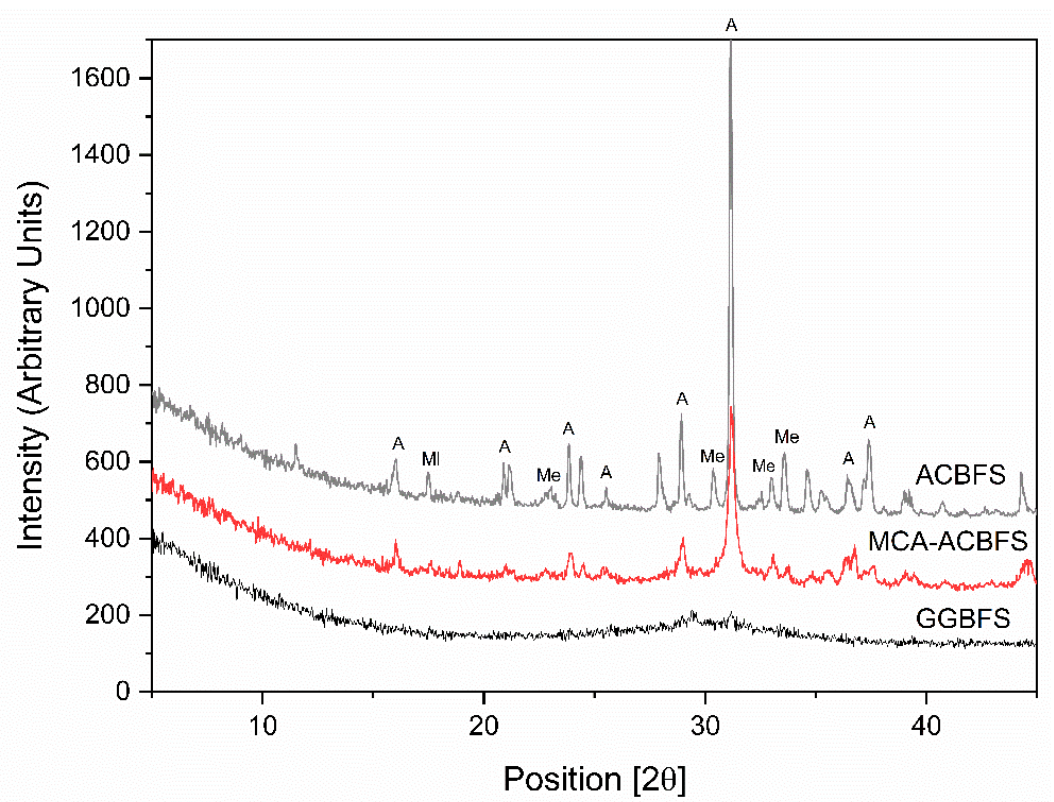

Figure 4. XRD pattern of ACBFS, MCA-ACBFS and GGBFS. 
XRD analysis of the alkali-activated pastes based on GGBFS and MCA-ACBFS revealed a formation of the aluminate-substituted calcium silicate hydrate (CASH) in both cases (Figure 5). The CASH phase is the main phase observed to form in sodium silicate activated GGBFS [31,32]. CASH was detected in XRD for both sodium silicate activated slags (Figure 5). The not-amorphized akermanite (A) phase was still visible after sodium silicate activation of the MCA-ACBFS. Akermanite seemed to be inert to the alkali activation process, thus complying with the latent reactivity of the water-cooled slag before the mechanical activation. Optimization of the grinding parameters could produce higher degree of amorphization for the akermanite (A) phase, providing a final phase composition similar to the GGBFS.

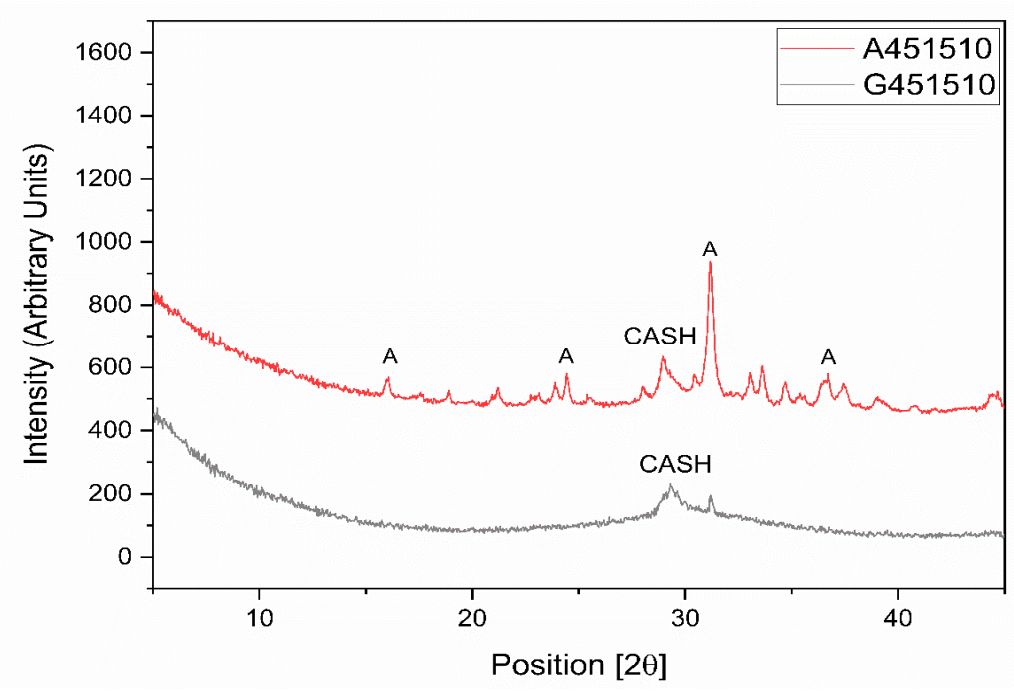

Figure 5. XRD diagrams for sodium silicate activated slags with water to binder $(\mathrm{w} / \mathrm{b})=0.45$, alkali modulus $(\mathrm{AM})=1.5$ and sodium silicate $(\mathrm{SS})=10 \%$.

All mortar samples made from ACBFS and GGBFS, with alkali modulus 1 and solid solution of $10 \%$, showed an acceptable workability. Mortar samples made from MCA-ACBFS presented a lower slump flow than the GGBFS-based samples. It was related to a finer particle size distribution and a higher specific surface area caused by the applied MCA process (Figures 3 and 6) [33]. The increased $\mathrm{w} / \mathrm{b}$ ratio enhanced the workability of mixes activated with 10 and $15 \mathrm{wt} . \%$ of the SS. Mortars activated with $20 \mathrm{wt} . \%$ of SS showed a similar workability independently of the used AM.

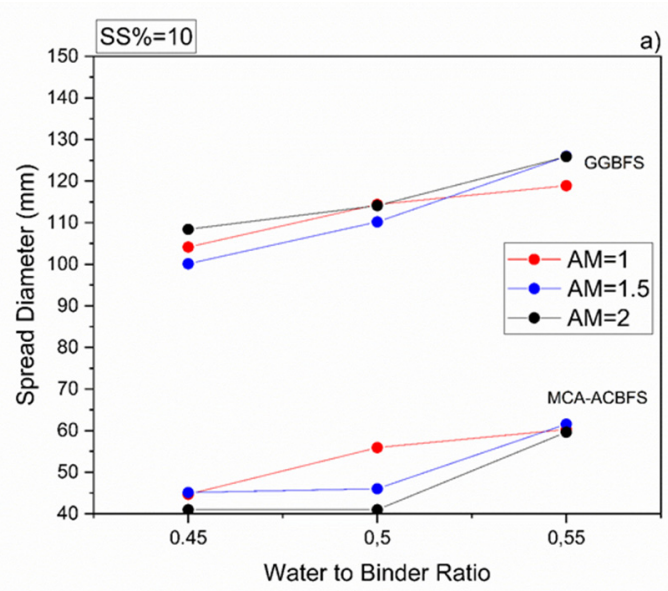

(a)

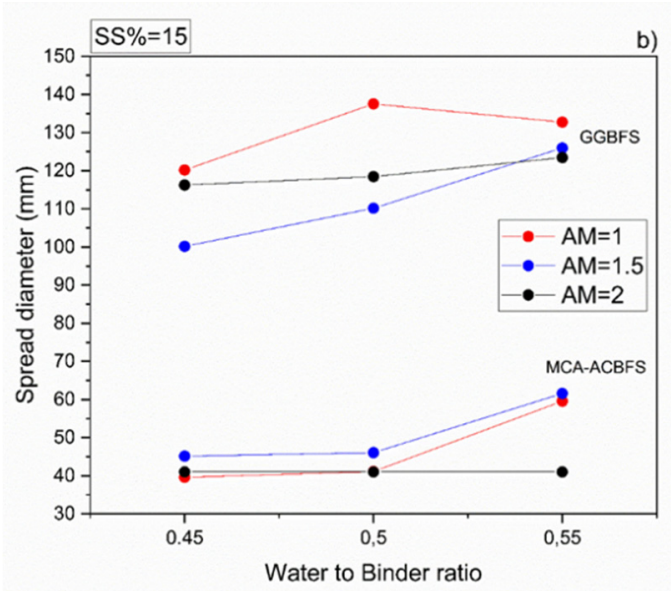

(b)

Figure 6. Cont. 


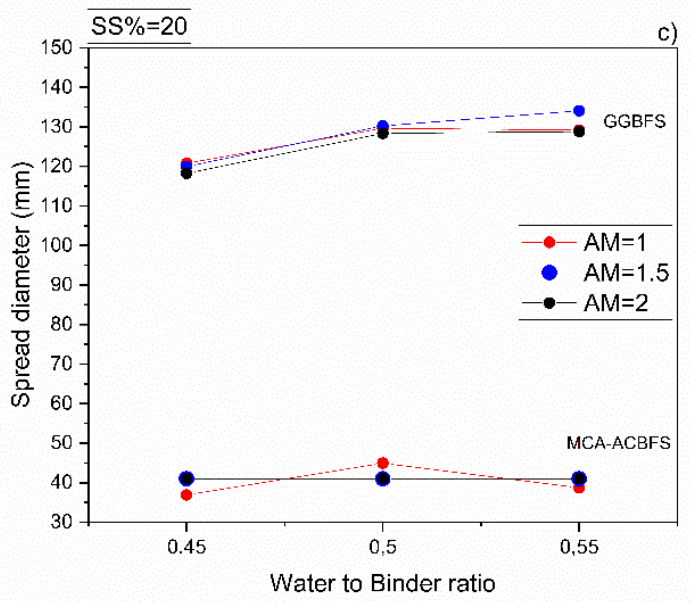

(c)

Figure 6. Workability of sodium silicate activated mortars containing MCA-ACBFS and GGBFS as precursors, for different w/b, alkali modulus and solid solution content, respectively. (a) $10 \%$, (b) $15 \%$ and (c) $20 \%$.

The MCA-ACBFS based mortars activated with the SS having the alkali modulus of 1 and containing $10 \mathrm{wt} . \%$ of the SS alkali activator showed comparable or higher 28-day compressive strength values than the GGBFS (Figure 7). Mortars based on MCA-ACBFS reached 20-40 MPa while those based on the water-cooled GGBFS reached 20-30 MPa. In general, a higher w/b ratio decreased the compressive strength for all tested mortars.

The compressive strength values tended to increase at lower $\mathrm{w} / \mathrm{b}$ ratios for both types of the used slags. Usually the $\mathrm{w} / \mathrm{b}$ ratio had a smaller effect on mechanical properties in the case of the AAM and the chemical composition of the precursor was the dominant factor [34]. In this case, however, the initial chemical composition of both slags was very similar. MCA-ACBFS showed decreased compressive strength values at lower $\mathrm{w} / \mathrm{b}$ ratios. The same trend was observed for higher alkali modulus $(\mathrm{Ms}=1.5)$ and for both analyzed slags. Higher w/b ratio gave decreased strength measured after 7 and 28 days. The higher amount of water presumably increased the binder matrix porosity, which lowered the measured strength. Increasing the alkali modulus to 1.5 strongly influenced the mechanical properties at 7 days for GGBFS samples (Figure 8). Extremely low values were registered accompanied by not fully dried samples with greenie color in the inner part.

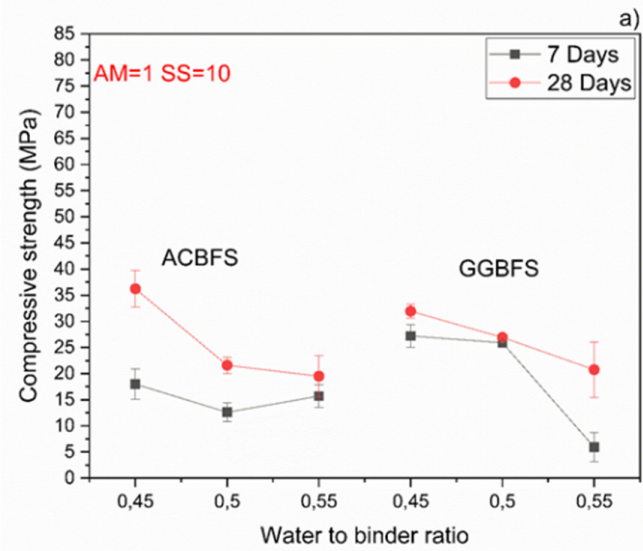

(a)

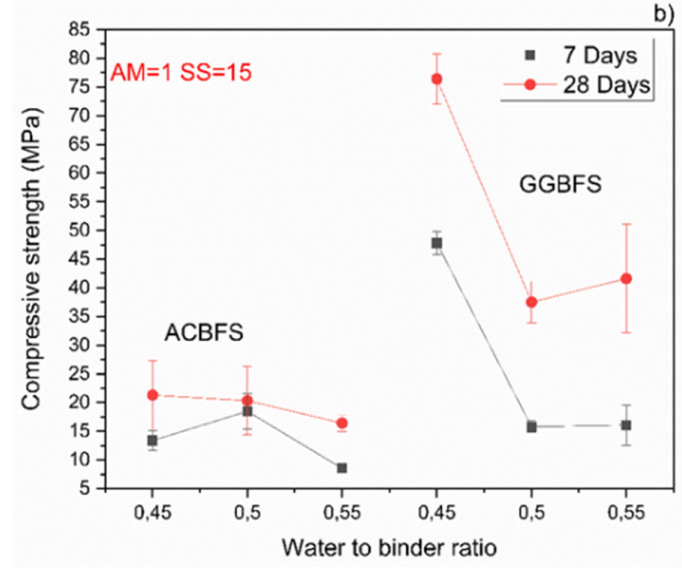

(b)

Figure 7. Cont. 


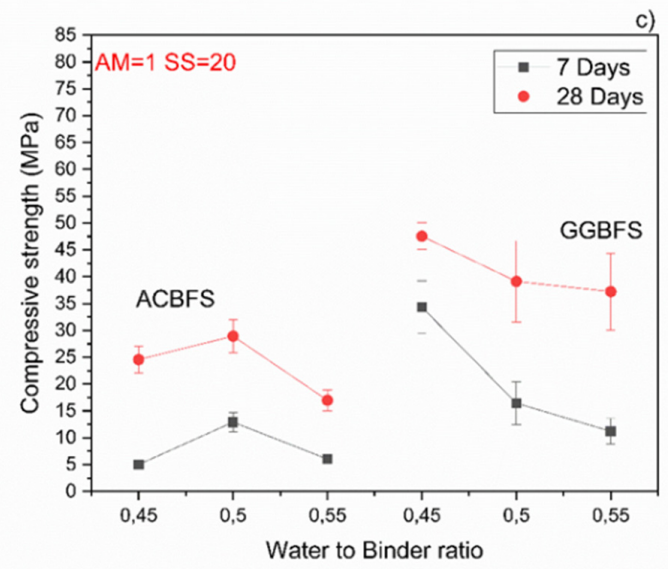

(c)

Figure 7. Effects of $\mathrm{w} / \mathrm{b}$ ratio and SS amount on 7- and 28-days compressive strength values for mixes activated with sodium silicate having Ms = 1 and SS content of; (a) $10 \%$; (b) $15 \%$; (c) $20 \%$.

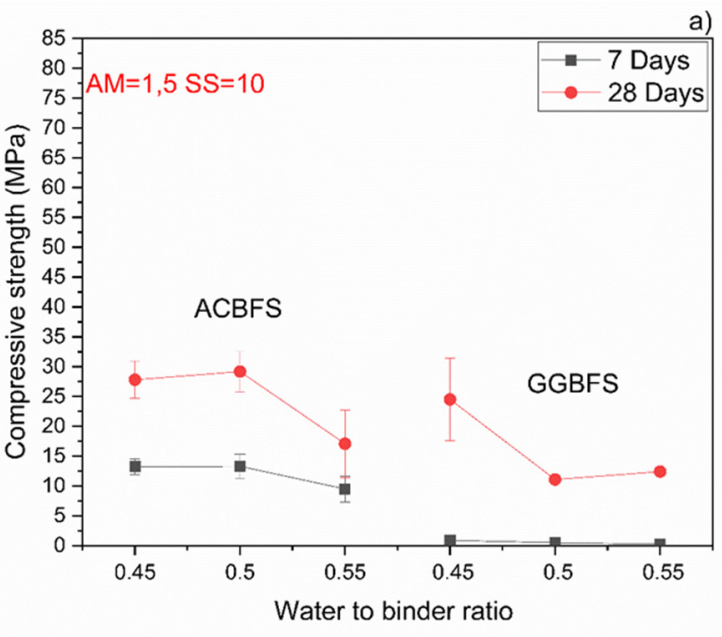

(a)

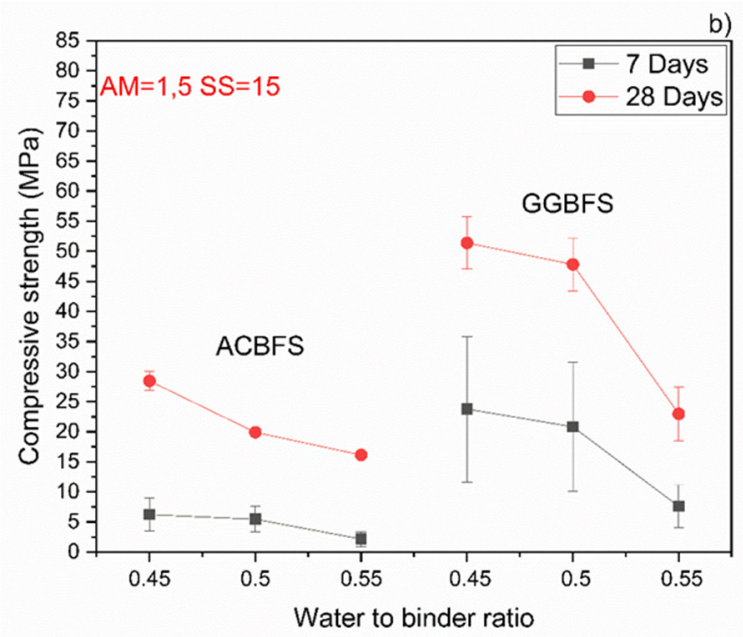

(b)

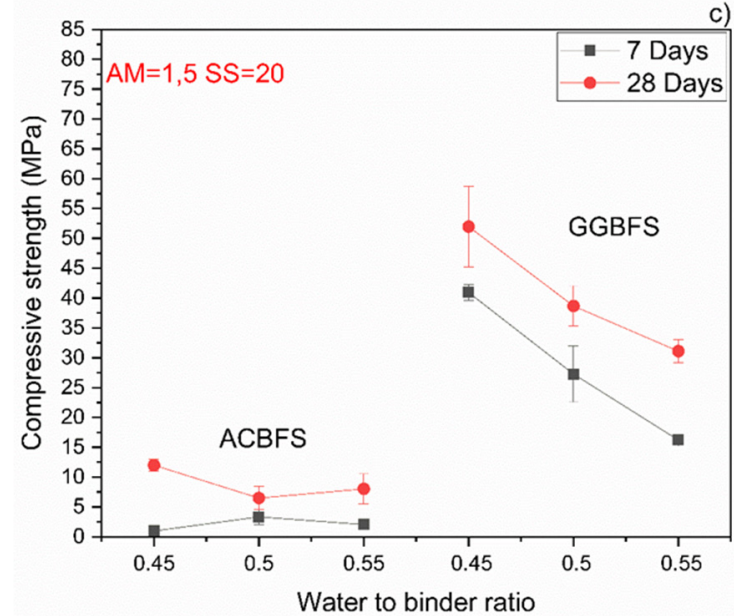

(c)

Figure 8. Effects of $\mathrm{w} / \mathrm{b}$ ratio and SS amount on 7- and 28-days compressive strength values for mixes activated with sodium silicate having Ms = 1,5 and SS content of; (a) $10 \%$; (b) $15 \%$; (c) $20 \%$. 
The workability of the GGBFS-based concrete was not affected by a higher alkali modulus (Figure 6). On the contrary, mixes based on the MCA-ACBFS, showed a decreased slump flow and a rapid setting at higher AM.

Both effects were observed also by others and were related to a higher $\mathrm{pH}$ values which accelerated dissolution of the slag [24,27,35-37]. Higher alkali modulus of the used SS activator decreased the compressive strength values in both slags (Figure 9). In the case of mixes based on the MCA-ACBFS, higher alkali modulus of the SS activator and its higher dosage decreased the compressive strength values from $40 \mathrm{MPa}$ to $20 \mathrm{MPa}$.

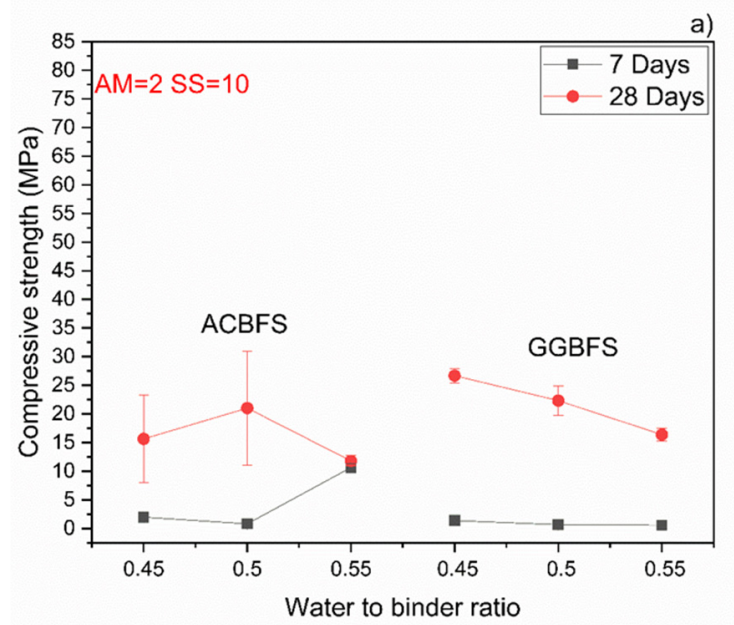

(a)

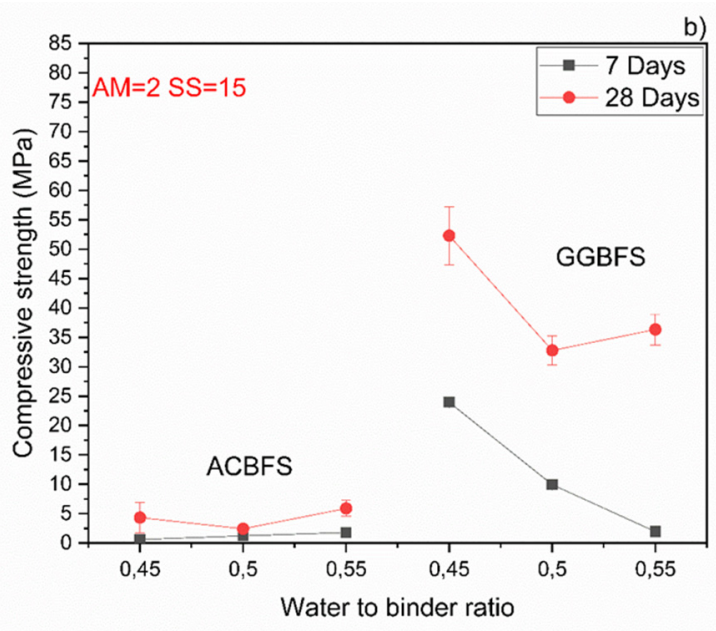

(b)

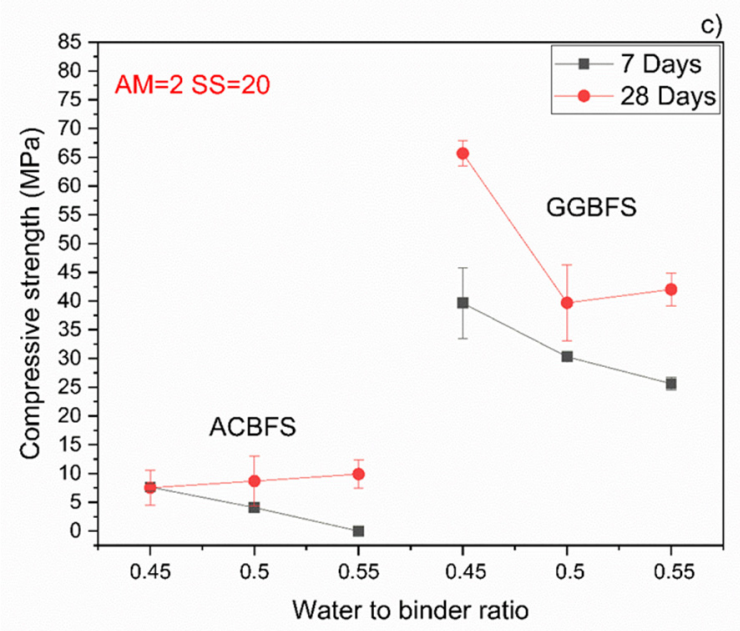

(c)

Figure 9. Behavior of the compressive strength evolution with different $w / b$ for MCA-ACBFS and GGBFS sodium silicate activated samples with $\mathrm{Ms}=2$ and solid solution content. (a) $10 \%$; (b) $15 \%$; (c) $20 \%$.

SEM-EDS analysis was performed on alkali-activated slag samples having $\mathrm{w} / \mathrm{b} 0.45$, alkali modulus of 1.5 and $10 \%$ of solid solution (Figure 10). The alkali-activated GGBFS matrix consisted of homogenous appearing phases surrounding unreacted GGBFS particles and sand. Some air voids and micro cracks were observed as well. On the contrary, the microstructure of the alkali-activated MCA-ACBFS matrix was very inhomogeneous and contained a large amount of fine unreacted MCA-ACBFS particles. These observations complied with the XRD graphs, which shows that after alkali activation the not-amorphized phases have not reacted with the alkali environment (Figure 5). 


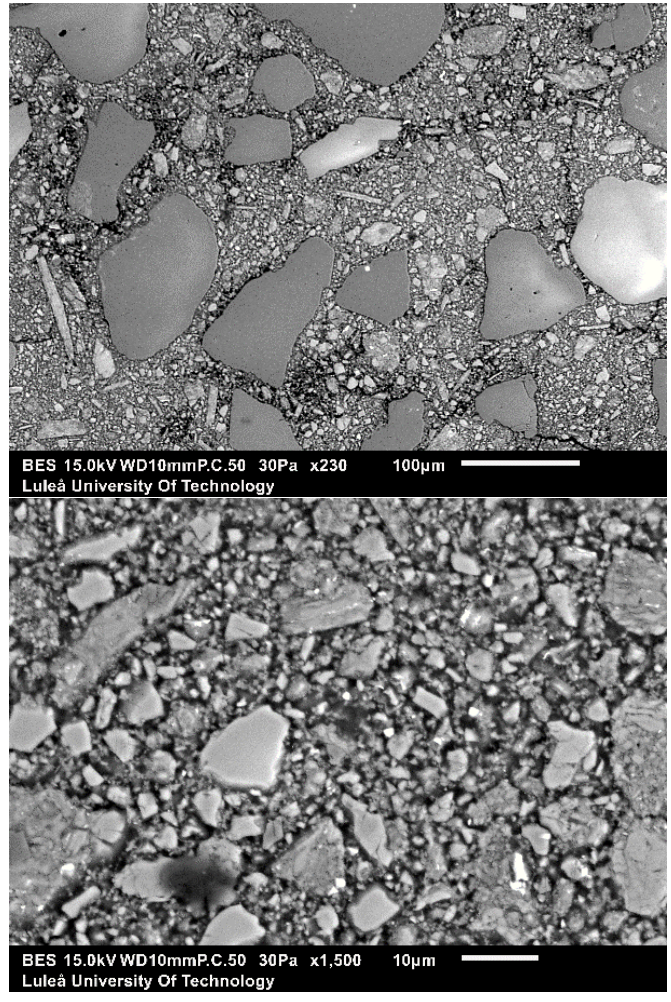

(a)

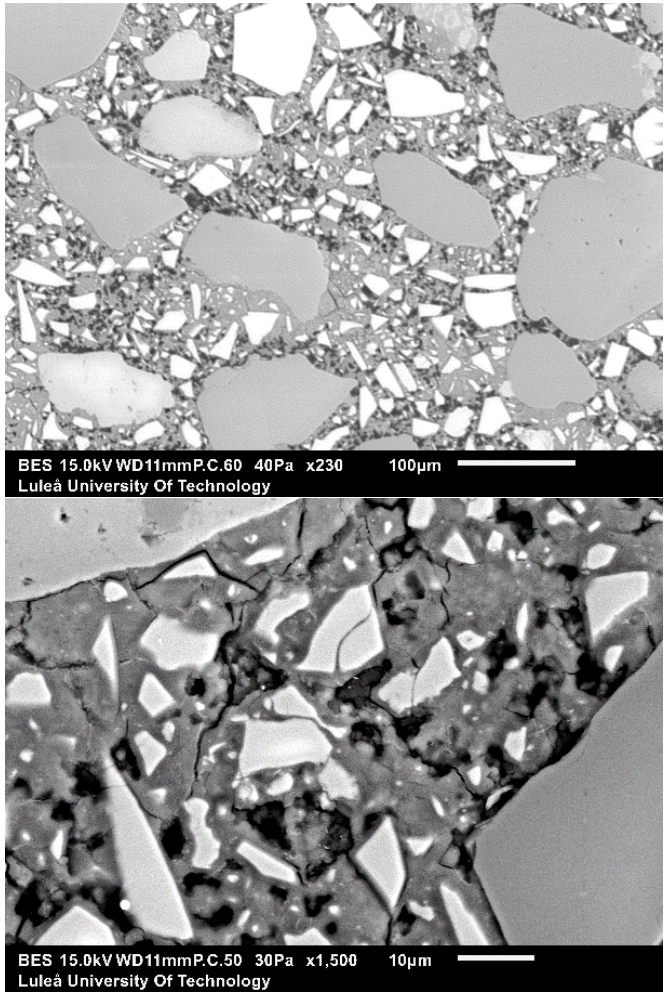

(b)

Figure 10. Micrographs of the 28-days old alkali-activated slag samples with $w / b=0.45, A M=1.5$ and SS $=10 \%$ using as a precursor (a) GGBFS at $\times 230$ and $\times 1500$ of magnification; and (b) MCA-ACBFS at $\times 230$ and $\times 1500$ of magnification.

The chemical composition of the solidified binder matrix was characterized by the SEM-EDX spot analysis. The calculated $\mathrm{Ca} / \mathrm{Al}$ and $\mathrm{Ca} / \mathrm{Si}$ ratios are shown in Figure 11 and Table 4 . The $\mathrm{Ca} / \mathrm{Si}$ atomic ratio ranged between 0.6 and 1.5 , which corresponds to the CASH type phases and also supports the XRD test results (Figure 5).

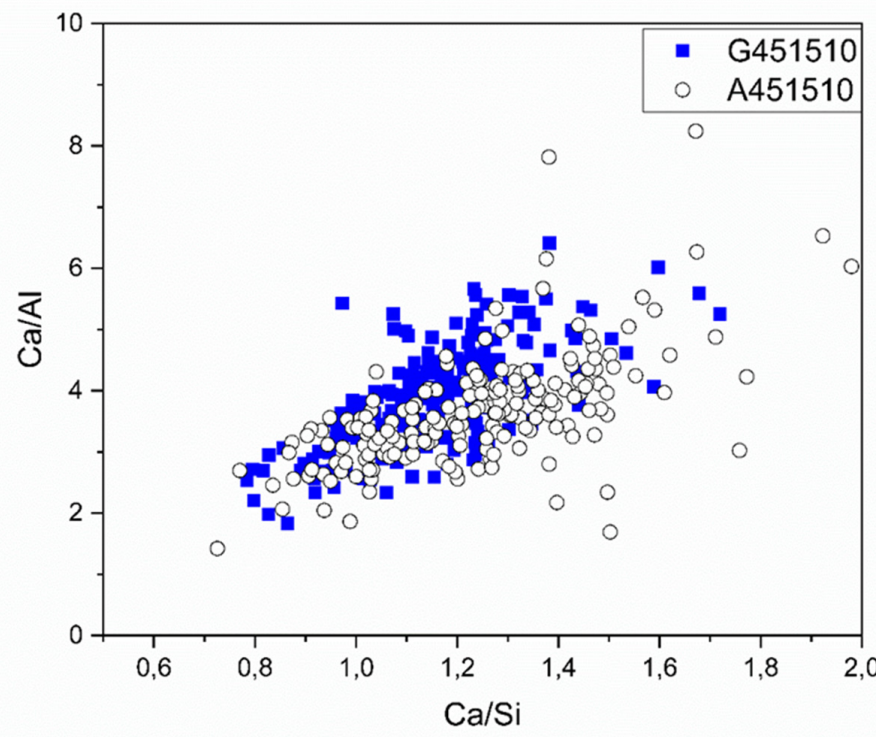

Figure 11. SEM-EDX test results shown as $\mathrm{Ca} / \mathrm{Al}$ vs $\mathrm{Ca} / \mathrm{Si}$ ratio collected on 28-days old samples in the binder matrix. 
Table 4. Average $\mathrm{Ca} / \mathrm{Si}$ and $\mathrm{Al} / \mathrm{Ca}$ atomic ratios calculated based on the SEM-EDX test results.

\begin{tabular}{ccc}
\hline & Al/Ca & Ca/Si \\
\hline AA-GGBFS & $3.87641 \pm 0.83344$ & $1.1443 \pm 0.16461$ \\
AA-MCA-ACBFS & $3.62735 \pm 0.89978$ & $1.22593 \pm 0.21916$ \\
\hline
\end{tabular}

The ternary diagram (Figure 12) based on the data obtained from the SEM-EDX spot analysis showed a similar distribution for both slags solidified by sodium silicate activation, indicating a dominance of CASH and sodium aluminosilicate hydrate (NASH) [31,38].

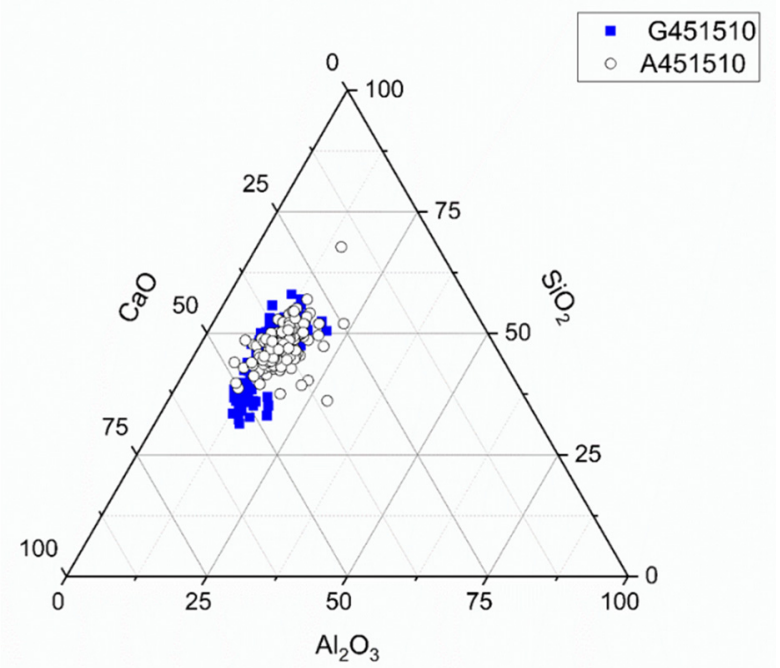

Figure 12. Ternary diagram for sodium silicate activated slags (MCA-ACBFS and GGBFS), with w/b 0.45 , alkali modulus 1 , after 28 days of hydration.

\section{Conclusions}

Decreased intensities and increased area of the XRD peaks indicated an increased amorphization of the treated samples after application of the optimized mechanical activation process. SEM-EDX analysis showed a quite similar composition of the solidified binder matrixes in both tested slags. The main conclusions can be summarized as follow:

- Inert and crystalline air-cooled slag can be amorphized and have enhanced reactivity by application of an optimized mechanical activation process.

- $\quad$ MCA-ACBFS can be considered as precursor for alkali activated systems.

- Workability of ACBFS is strongly influenced by the used mechanical treatment and sodium silicate activator.

- The highest compressive strength of mortars based on MCA-ACBFS was achieved for mixes having the $w / b=0.45$ and activated with $10 \%$ of SS. The AM was 1 .

- The highest compressive strength of mortars based on GGBFS was achieved for mixes having the $\mathrm{w} / \mathrm{b}=0.45$ and activated with $10 \%$ of SS. The AM was 1.5 .

Further tests are needed in order to evaluate the suitability of using MCA-ACBFS as a precursor for AAM. Standardized test methods should be used for full scale comparison with traditional materials.

Author Contributions: Conceptualization, A.C. and I.T.; software, M.R.; investigation, I.T., M.R., A.H. and A.K.; data curation, I.T.; writing-original draft preparation, I.T.; writing-review and editing, A.C.; visualization, I.T.; supervision, A.C.; funding acquisition, A.C. All authors have read and agreed to the published version of the manuscript.

Funding: This work was supported by the Swedish Research Council - FORMAS.

Conflicts of Interest: The authors declare no conflict of interest. 


\section{References}

1. Scrivener, K.L. Options for the future of cement. Indian Concr. J. 2014, 88, 11-21.

2. Chidiac, S.E.; Panesar, D.K. Evolution of mechanical properties of concrete containing ground granulated blast furnace slag and effects on the scaling resistance test at 28 days. Cem. Concr. Compos. 2008, 30, 63-71. [CrossRef]

3. Provis, J.L.; Bernal, S.A. Geopolymers and related alkali-activated materials. Annu. Rev. Mater. Res. 2014, 44, 299-327. [CrossRef]

4. Cwirzen, A.; Engblom, R.; Punkki, J.; Habermehl-Cwirzen, K. Effects of curing: Comparison of optimised alkali-activated PC-FA-BFS and PC concretes. Mag. Concr. Res. 2014, 66, 315-323. [CrossRef]

5. Chi, M.; Chang, J.; Huang, R. Strength and Drying Shrinkage of Alkali-Activated Slag Paste and Mortar. Adv. Civ. Eng. 2012, 2012, 579732. [CrossRef]

6. Provis, J.L. Geopolymers and other alkali activated materials: Why, how, and what? Mater. Struct. 2014, 47, 11-25. [CrossRef]

7. Ridgeway, P. Dry Slag Granulation with Integrated Heat Recovery. 2011. Available online: https://www. researchgate.net/publication/264383880 (accessed on 5 July 2019).

8. Caijun, S. Steel Slag-Its Production, Processing, Characteristics, and Cementitious Properties. J. Mater. Civ. Eng. 2004, 16, 230-236. [CrossRef]

9. Zhang, H.; Wang, H.; Zhu, X.; Qiu, Y.-J.; Li, K.; Chen, R.; Liao, Q. A review of waste heat recovery technologies towards molten slag in steel industry. Appl. Energy 2013, 112, 956-966. [CrossRef]

10. Das, B.; Prakash, S.; Reddy, P.S.R.; Misra, V.N. An overview of utilization of slag and sludge from steel industries. Resour. Conserv. Recycl. 2007, 50, 40-57. [CrossRef]

11. Shi, C.; Qian, J. High performance cementing materials from industrial slags-A review. Resour. Conserv. Recycl. 2000, 29, 195-207. [CrossRef]

12. Sadek, D.M. Effect of cooling technique of blast furnace slag on the thermal behavior of solid cement bricks. J. Clean. Prod. 2014, 79, 134-141. [CrossRef]

13. Balaz, P. High-Energy Milling. In Mechanochemistry in Nanoscience and Minerals Engineering; Springer: Berlin/Heidelberg, Germany, 2008; pp. 103-132.

14. Baláž, P.; Achimovičová, M.; Baláž, M.; Billik, P.; Cherkezova-Zheleva, Z.; Criado, J.M.; Delogu, F.; Dutková, E.; Gaffet, E.; Gotor, F.J. Hallmarks of mechanochemistry: From nanoparticles to technology. Chem. Soc. Rev. 2013, 42, 7571-7637.

15. Aglietti, E.F.; Lopez, J.M.P.; Pereira, E. Mechanochemical effects in kaolinite grinding. I. Textural and physicochemical aspects. Int. J. Miner. Process. 1986, 16, 125-133. [CrossRef]

16. Boldyrev, V.V. Mechanochemistry and mechanical activation of solids. Russ. Chem. Rev. 2006, 75, 177. [CrossRef]

17. Frost, R.L.; Makó, É.; Kristóf, J.; Horváth, E.; Kloprogge, J.T. Mechanochemical treatment of kaolinite. J. Colloid Interface Sci. 2001, 239, 458-466. [CrossRef] [PubMed]

18. Frost, R.L.; Horváth, E.; Makó, É.; Kristóf, J.; Cseh, T. The effect of mechanochemical activation upon the intercalation of a high-defect kaolinite with formamide. J. Colloid Interface Sci. 2003, 265, 386-395. [CrossRef]

19. Tole, I.; Habermehl-Cwirzen, K.; Cwirzen, A. Mechanochemical activation of natural clay minerals: An alternative to produce sustainable cementitious binders-Review. Mineral. Petrol. 2019, 113, 449-462. [CrossRef]

20. Rossen, J.E.; Scrivener, K.L. Optimization of SEM-EDS to determine the C-A-S-H composition in matured cement paste samples. Mater. Charact. 2017, 123, 294-306. [CrossRef]

21. Schindelin, J.; Arganda-Carreras, I.; Frise, E.; Kaynig, V.; Longair, M.; Pietzsch, T.; Preibisch, S.; Rueden, C.; Saalfeld, S.; Schmid, B.; et al. Fiji: An open-source platform for biological-image analysis. Nat. Methods 2012, 9, 676. [CrossRef]

22. Schneider, C.A.; Rasband, W.S.; Eliceiri, K.W. NIH Image to ImageJ: 25 years of image analysis. Nat. Methods. 2012, 9, 671. [CrossRef]

23. Schindelin, J.; Rueden, C.T.; Hiner, M.C.; Eliceiri, K.W. The ImageJ ecosystem: An open platform for biomedical image analysis. Mol. Reprod. Dev. 2015, 82, 518-529. [CrossRef] [PubMed]

24. Bakharev, T.; Sanjayan, J.G.; Cheng, Y.-B. Alkali activation of Australian slag cements. Cem. Concr. Res. 1999, 29, 113-120. [CrossRef] 
25. McGannon, H.E. The Making. In Shaping and Treating of Steel; USS-United States Steel: Pittsburgh, PA, USA, 1971.

26. Li, Y.; Sun, Y. Preliminary study on combined-alkali-slag paste materials. Cem. Concr. Res. 2000, 30, 963-966. [CrossRef]

27. Adam, A. Strength and Durability Properties of Alkali Activated Slag and Fly ash-Based Geopolymer Concrete. Ph.D. Thesis, RMIT University, Melbourne, Australia, 2009.

28. Chang, J.J. A study on the setting characteristics of sodium silicate-activated slag pastes. Cem. Concr. Res. 2003, 33, 1005-1011. [CrossRef]

29. Balczár, I.; Korim, T.; Hullár, H.; Boros, A.; Makó, É. Manufacture of air-cooled slag-based alkali-activated cements using mechanochemical activation. Constr. Build. Mater. 2017, 137, 216-223. [CrossRef]

30. Tole, I.; Habermehl-Cwirzen, K.; Rajczakowska, M.; Cwirzen, A. Activation of a raw clay by mechanochemical process-effects of various parameters on the process efficiency and cementitious properties. Materials 2018, 11, 1860. [CrossRef] [PubMed]

31. Wang, S.-D.D.; Scrivener, K.L. Hydration products of alkali activated slag cement. Cem. Concr. Res. 1995, 25, 561-571. [CrossRef]

32. Garcia-Lodeiro, I.; Palomo, A.; Fernández-Jiménez, A.; Macphee, D.E. Compatibility studies between $\mathrm{N}-\mathrm{A}-\mathrm{S}-\mathrm{H}$ and C-A-S-H gels. Study in the ternary diagram $\mathrm{Na}_{2} \mathrm{O}-\mathrm{CaO}-\mathrm{Al}_{2} \mathrm{O}_{3}-\mathrm{SiO}_{2}-\mathrm{H}_{2} \mathrm{O}$. Cem. Concr. Res. 2011, 41, 923-931. [CrossRef]

33. Ghasemi, Y.; Emborg, M.; Cwirzen, A. Exploring the relation between the flow of mortar and specific surface area of its constituents. Constr. Build. Mater. 2019, 211, 492-501. [CrossRef]

34. Bernal, S.A.; Provis, J.L. Impact of Water Content on the Performance of Alkali-Activated Slag Concretes. In Proceedings of the Sixth International Conference on Durability of Concrete Structures (ICDCS 2018), Leeds, UK, 18-20 July 2018; pp. 143-148.

35. Humad, A.M.; Provis, J.L.; Cwirzen, A. Alkali activation of a high MgO GGBS—Fresh and hardened properties. Mag. Concr. Res. 2017, 70, 1256-1264. [CrossRef]

36. Lee, N.K.; Lee, H.K. Setting and mechanical properties of alkali-activated fly ash/slag concrete manufactured at room temperature. Constr. Build. Mater. 2013, 47, 1201-1209. [CrossRef]

37. Qureshi, M.N.; Ghosh, S. Workability and setting time of alkali activated blast furnace slag paste. Adv. Civ. Eng. Mater. 2013, 2, 62-77. [CrossRef]

38. Myers, R.J.; Bernal, S.A.; Provis, J.L. Phase diagrams for alkali-activated slag binders. Cem. Concr. Res. 2017, 95, 30-38. [CrossRef] 